\title{
Reforma del Cc. de Portugal: Los animales como seres sintientes
}

Keywords: estatuto jurídico animal; tratado de propiedad; seres sintientes; Código civil

El 22 de Diciembre de 2016 nos permite terminar el año con una gran noticia, que es el cambio de estatuto jurídico de los animales en el Código civil portugués, de cosas en propiedad a seres sintientes.

En tal fecha, el Parlamento portugués aprobó por unanimidad que los animales dejan de ser cosas en propiedad, tal y como, hasta la fecha, venía siendo regulado por el Código civil en los respectivos artículos, entre otros: 1302[1], 1318 y 1323[2], del libro III, referido al “Direito das Coisas”, en congruencia con la tradición romana, que se ha plasmado en la gran mayoría de los Códigos continentales (europeos y Latinoamericanos) y ha sido reconocido por los tratados de Derecho civil[3]. En esta línea, Portugal no era, hasta la fecha ninguna excepción al régimen de la propiedad sobre los animales, considerados como cosas muebles que es el estatuto jurídico imperante en los sistemas jurídicos occidentales.

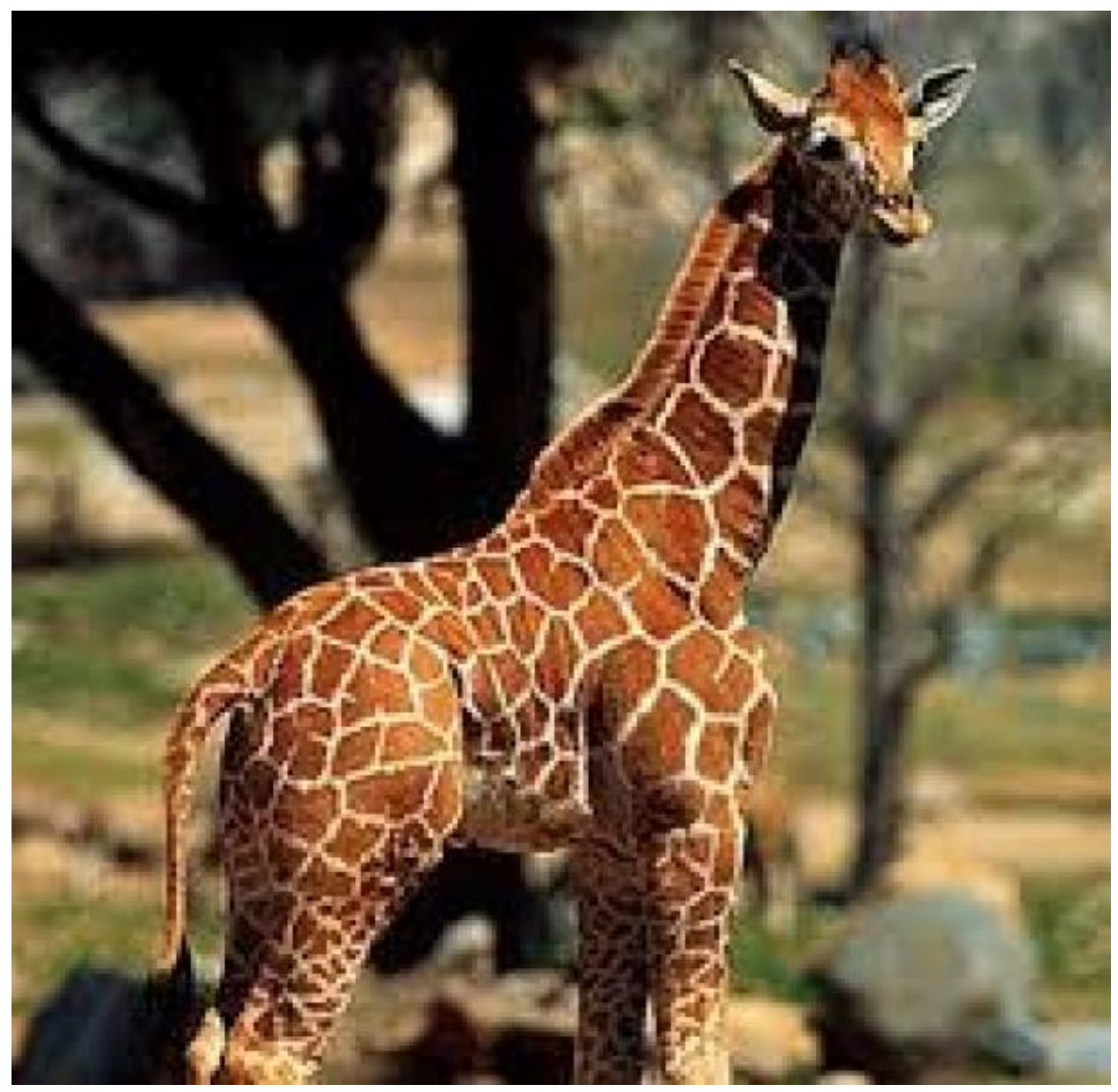

La tramitación de esta importante reforma de la condición jurídica de los animales ha tenido un largo recorrido, culminado con el éxito de una propuesta que, como veremos, presenta rasgos de originalidad, 
respecto a otras reformas del estatuto jurídico de los animales llevadas a cabo por otros países, ya en la década de los años 90 del pasado siglo XX y en la primera década del S.XXI. Portugal se sitúa, con esta reforma, en un lugar preeminente en cuanto a la trasposición a un texto jurídico de los últimos avances de la ciencia del Bienestar Animal, que, con firmeza y solidez viene afirmando que los animales son seres sintientes ("sentient beings")[4].

En efecto, la propuesta inicial de modificación del Código Civil fue presentada el 13 de Mayo de 2016, por los siguientes partidos: PAN (Personas, Animales, Naturaleza), Partido Socialista (PS), Bloque de Izquierdas (BE) y Partido Social Demócrata (PSD). El redactado final, consiguió la mayoría absoluta de los votos después del debate en la Comisión de Asuntos Constitucionales, Derechos, Libertades y Garantías (Comissao de Assuntos Constitucionais, Direitos, Liberdades e Garantias). La propuesta fue aprobada por todos los partidos sin excepción (PAN, PSD, PS, BE, CDU y CDS-PP), a favor del reconocimiento de los animales como seres sintientes, incluidos en una sección separada del Código civil, distinta del Libro destinado al régimen de la propiedad, lo que viene a establecer un régimen jurídico especial para los animales. Sin duda, una decisión valiente y original, que abre una nueva frontera a las reformas de otros Códigos civiles, como el español, que aún se resisten a modificar el estatuto jurídico de los animales y a dejar de considerarlos cosas.

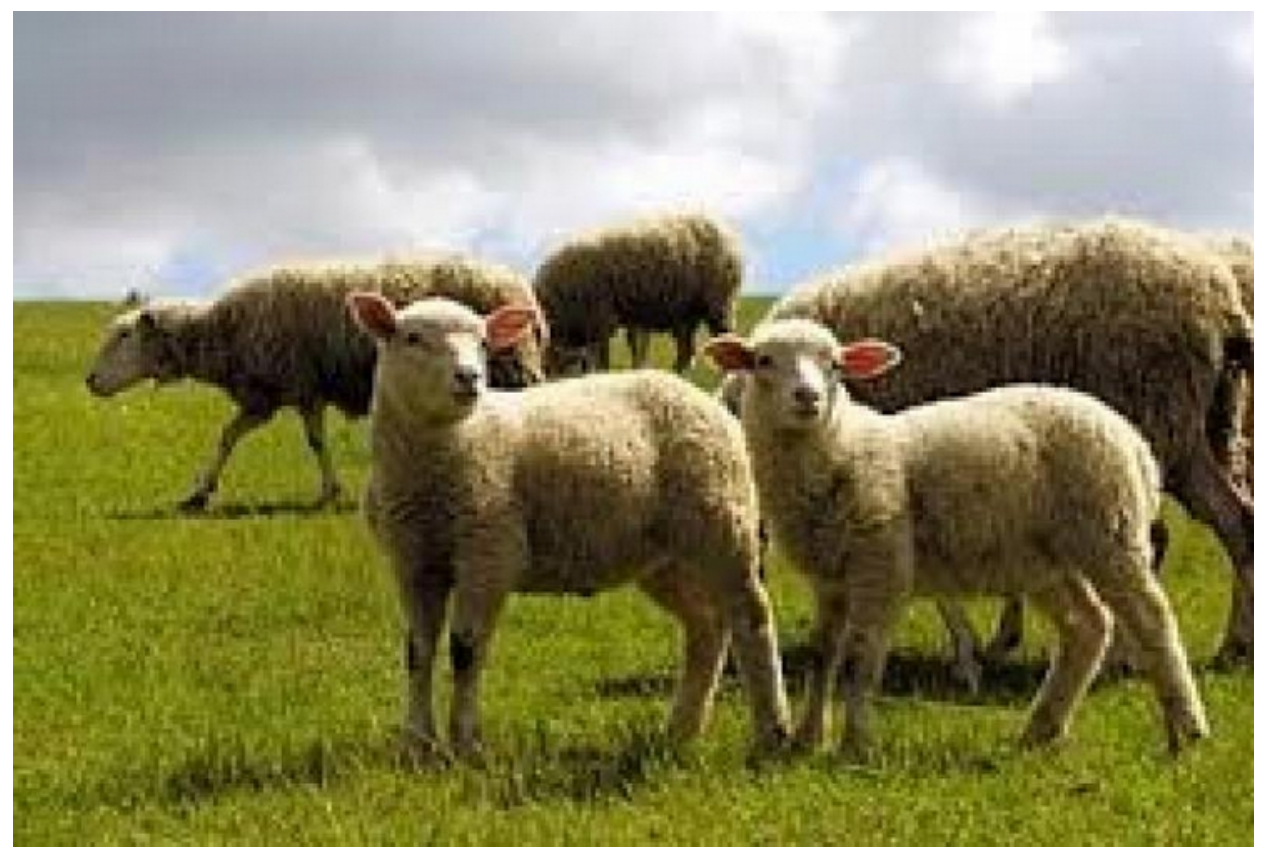

Justo es reconocer que el mérito de esta iniciativa se debe al partido portugués que en sus siglas ya lleva la defensa de los animales como enseña de sus políticas, me refiero al PAN, que cuenta con un único representante en la cámara, el diputado André Silva. Sin embargo, no deben ser olvidados los esfuerzos conjuntos, tanto de los restantes representantes de los partidos políticos mencionados, como las aportaciones doctrinales que han llevado a cabo a lo largo de la tramitación[5], los expertos como el catedrático de la Facultad de Derecho de la Universidad de Lisboa, Prof. Fernando Araujo[6] y la acción coordinada de Inés Real, Proveedora dos Animais del Ayuntamiento de Lisboa[7]

En suma, la modificación del estatuto jurídico de los animales se refleja en el artículo 1, con el siguiente tenor:

"Esta ley establece un estatus proprio de los animales, reconociendo su naturaleza de seres vivos sensibles."

Tal modificación no implica de forma inmediata la atribución de personalidad jurídica a los animales, sino que -y ahí radica uno de los aspectos mas destacables de la reforma- comporta una nueva clasificación y la creación de un concepto jurídico nuevo, que sitúa a los animales en una categoría jurídica “a se”, que no es otra que la de “Animales”. 
Es decir, el Código civil portugués reconoce que los animales, tanto por su condición objetiva de seres sintientes (como predica la ciencia), como por su condición subjetiva de seres vivos, no encajan como cosas inertes en la clasificación de las cosas en propiedad y, por ello, ha creado una tercera figura jurídica, la de los animales, que no se confunde ni con las cosas ni con los seres humanos, que, jurídicamente, tendemos a denominar "personas”, aunque la categoría de “personas”, en sí misma, no es más que una abstracción categorizada de la representación con la que algo (una sociedad, un ente, un conjunto de voluntades, un ser humano también) actúa en el Derecho, de ahí la gran expansión del concepto de “persona” en el ámbito jurídico. Los animales, pues, aparecen a partir de ahora en el Código civil portugués como seres dotados de sensibilidad y objeto de relaciones jurídicas. Entre otras consecuencias, el reconocimiento de los animales como categoría jurídica independiente, lleva aparejada la posibilidad de indemnización en caso de muerte o lesiones del animal, el establecimiento de la figura del cuidador de animales en caso de divorcio y la inembargabilidad de los animales domésticos.

La referida enmienda, ha supuesto una reorganización sistemática del Código civil, que queda de la siguiente forma[8]: Se ha añadido un Subtítulo I-A al libro I del Título II, bajo la denominación de “Animales”, que integra los artículos 201-B y 201-D[9].

El Parlamento portugués, sin embargo, rechazó el Proyecto de ley destinado a mejorar el sistema de sanciones previstas en el Código Penal respecto al maltrato animal. No se ha logrado castigar como delito el abandono del animal, independientemente de que ello ponga en peligro la vida o integridad física del mismo (como, en cambio, sí ocurre en España desde la última reforma del art. 337 por la LO1/2015 de de Julio). Tampoco se ha conseguido penalizar la muerte del animal, aunque no haya sido precedida de malos tratos, ni se ha penalizado el maltrato de otros animales, independientemente de su categoría o uso, como ocurre en particular con los animales de producción.

En suma, la reforma del Código civil portugués abre una puerta importante a la reflexión jurídica, se adelanta a otras reformas acerca de los animales ya realizadas por otros Códigos civiles europeos[10] y Latinoamericanos (en especial, a la llevada a cabo en 2015 en Francia[11] y Colombia[12]) y dignifica la condición jurídica de los animales apartándolos de la condición de cosas en propiedad.

He estado pensando estos días que en la causa animal los años se cuentan por victorias. No es una expresión de optimismo irreflexivo. Muy al contrario. Es una frase que refleja una contabilidad muy bien llevada: no hay año, al menos desde que este milenio ha comenzado, en que el transcurso del tiempo no nos haya deparado grandes alegrías en forma de conquistas para los animales, desde prohibiciones relativas a los animales de producción tendentes a mejorar sus pobres vidas, sanciones penales por maltrato (cada vez más próximas a proteger el bien jurídico de la vida animal por lo que ésta en sí misma vale), cambios en el estatuto jurídico animal, mejoras en el transporte, la experimentación y el sacrificio, aumento del interés por el estudio profesional sobre el Derecho Animal y de los cursos destinados a impartirlo en las Universidades.

En definitiva, cada paso adelante es un avance sin retroceso por y para los animales. Hagamos que el 2017 sea una año más de victoria. Los animales no pueden esperar.

LA EDITORA

Teresa Giménez-Candela Catedrática de Derecho Romano Directora del Master en Derecho Animal y Sociedad Directora del ICALP

Universitat Autònoma de Barcelona Sígueme en Facebook: https://www.facebook.com/editora.da

[1] Cc. portugués, art 1302: "Só as coisas corpóreas, móveis ou imóveis, podem ser objecto do direito de propriedade regulado neste código”.

[2] Cc. portugués, art. 1323.1: “ Aquele que encontrar animal ou outra coisa móvel perdida e souber a quem pertence deve restituir o animal ou a coisa a seu dono, ou avisar este do achado; se não souber a quem pertence, deve anunciar o achado pelo modo mais conveniente, 
atendendo ao valor da coisa e às possibilidades locais, ou avisar as autoridades, observando os usos da terra, sempre que os haja.

[3] Cfr. Para Portugal, MENEZES CORDEIRO, A., Tratado de Diretito Civil III. Parte Geral III. Coisas (Lisboa 2016), dedica el capítulo V de su tratado sobre la Propiedad a los animales (“Os Animais”), con una intersante reflexión acerca de la protección jurídica de los animales en el ámbito de la propiedad y a la justificación de la tutela jurídica de los mismos

[4] Vid. GIMÉNEZ-CANDELA, T., Seres sintientes; Brexit y los Animales. El legado del Reino Unido al Derecho Animal.

[5] Vid.el informe de la tramitación de la Comisión de Asuntos Constitucionales, Derechos, Libertades y Garantías de la Assembleia da Republica, de fecha de 21 de Diciembre de 2016

[6] ARAÚJO, F., A hora dos Direitos dos Animais (Coimbra 2003).

[7] Inés Real, Proveidora dos Animalis del Ayuntamiento de Lisboa desde 2014, es Licenciada en Derecho, Alumni del Máster en Derecho Animal y Sociedad (. ${ }^{\mathrm{a}}$ Ed.) de la Universitat Autònoma de Barcelona.

[8] Por supuesto, siendo tan reciente esta importante modificación, quedo a la espera de la entrada en vigor de la reforma para una lectura detenida del texto en cuestión y una ampliada reflexión crítica sobre la reforma a la que me refiero.

[9] La Sección II del Capítulo II del Título III del Libro II pasa a denominarse “ocupación de cosas y animales”.

[10] La cronología del cambio de estatuto jurídico animal de cosas a no-cosas, como primer paso a la "descosificación” de los animales en el sistema del Derecho civil, es la siguiente: Austria (ABGB, §285a) 1 de Julio de 1988; Alemania (BGB §90a) 20 de agosto de 1990; Suiza (ZGB §641ª) 4 de Octubre de 2002; Liechtenstein (Sachenrecht art.20ª) 14 de Mayo de 2003. También Cataluña (Cc. art. 511-1,3) 10 mayo de 2006.

[11] GIMÉNEZ-VANDELA, T., Una nueva Revolución Francesa: la modernización del Code civil

[12] CONTRERAS, C., Animales como seres sintientes protegidos por el Derecho Penal 